\title{
Environmental tobacco smoke and mortality in Chinese women who have never smoked: prospective cohort study
}

\author{
Wanqing Wen, Xiao Ou Shu, Yu-Tang Gao, Gong Yang, Qi Li, Honglan Li, Wei Zheng
}

\begin{abstract}
Objective To evaluate the association of environmental exposure to tobacco smoke from husbands and from work, as well as from family members in early life, with all cause mortality and mortality due to cancer or cardiovascular disease in Chinese women.

Design Ongoing prospective cohort study in Shanghai, China. Participants Of 72829 women who had never smoked, 65180 women provided information on smoking by their husbands, and 66520 women provided information on exposure to tobacco smoke at work and in early life from family members.

Main outcome measures All cause mortality and cause specific mortality with the main focus on cancer and cardiovascular disease. Cumulative mortality according to exposure status, and hazard ratios.

Results Exposure to tobacco smoke from husbands (mainly current exposure) was significantly associated with increased all cause mortality (hazard ratio $1.15,95 \%$ confidence interval 1.01 to 1.31) and with increased mortality due to cardiovascular disease $(1.37,1.06$ to 1.78$)$. Exposure to tobacco smoke at work was associated with increased mortality due to cancer (1.19, 0.94 to 1.50$)$, especially lung cancer $(1.79,1.09$ to 2.93$)$. Exposure in early life was associated with increased mortality due to cardiovascular disease (1.26, 0.94 to 1.69$)$.

Conclusions In Chinese women, exposure to environmental tobacco smoke is related to moderately increased risk of all cause mortality and mortality due to lung cancer and cardiovascular disease.
\end{abstract}

\section{Introduction}

Evidence linking environmental tobacco smoke to the risk of coronary heart disease and lung cancer has been mounting over the past two decades. The excess risk of coronary heart disease and lung cancer from environmental tobacco smoke is estimated at about $15-35 \% .^{1-3}$ Environmental tobacco smoke may also be related to other diseases, such as chronic obstructive pulmonary disease and breast cancer, although the evidence is sparse and inconsistent. ${ }^{45}$ Studies on the relation between environmental tobacco smoke and mortality are few and most have limited statistical power. $^{6} 7$

A recent study published in the $B M J$, which found no relation between environmental tobacco smoke and tobacco related deaths, provoked intense debate. ${ }^{8-12}$ Although the authors of that study pointed out the limitations of previous epidemiological studies, such as misclassifying exposure by using the smoking status of spouses as a proxy and inadequate control of potential confounders ${ }^{13}$ those problems existed in their own study and were criticised by many readers.

We used data from the Shanghai women's health study-an ongoing prospective cohort study conducted in Shanghai, China - to examine the association of environmental tobacco smoke with mortality. The rate of smoking in Chinese men is high, but most Chinese women living in Shanghai do not smoke, so our study provides a good opportunity to evaluate this association in women. For the causes of death, we focused on cancer, especially lung cancer, which is most closely related to tobacco smoke, and cardiovascular disease, particularly stroke, a leading cause of death and disability in China.

\section{Methods}

\section{Shanghai women's health study}

Eligible women $(\mathrm{n}=81 \mathrm{170})$ were aged $40-70$ and lived in seven areas of urban Shanghai. ${ }^{14}$ In total, 75220 women (92.7\%) completed the baseline survey, which included a face to face interview and a self administered questionnaire, March 1997 to May 2000. Subsequently, $278(0.4 \%)$ women who were outside the eligible age range were excluded, leaving 74942 women in the baseline cohort. The cohort has been followed up every two years by face to face interviews. Data are also obtained from the Shanghai Cancer Registry and the Shanghai Death Registry at the end of each year as another way to obtain cancer and death outcomes. Only 2113 of these women (2.8\%) had ever smoked, and they were excluded from our analysis.

\section{The exposure and outcome}

The baseline survey asked participants questions about smoking and other lifestyle factors, for themselves and for their husbands, thereby obtaining information on women's exposure to environmental tobacco smoke from their husbands. Exposure was classified as current exposure (if the husband still smoked) or former exposure (if he had stopped smoking). Exposure was measured by the number of pack years (years of smoking multiplied by packs of 20 cigarettes) that the husband had smoked during the marriage. The baseline survey also recorded demographic details and disease history, reproductive history, family history, and dietary history.

The first follow-up survey was conducted from 2000 to 2002 and the second from 2002 to 2004 . Only 934 (1.3\%) women were lost to follow-up at the end of the second follow-up survey. About $99.8 \%$ of the participants (or their next of kin if they had died) were interviewed to obtain information on death and common diseases diagnosed after the baseline survey. Of 72983 living participants, 67163 (92.1\%) completed the lifestyle module of the questionnaire through a face to face interview. The status and 
total years of environmental exposure to tobacco smoke at work and in early life from family members were assessed on the basis of replies to the questions, "Were you regularly (one cigarette per day and over six months) exposed to smoke due to smoking of other people at work and how many years did that occur?" "Were you regularly (one cigarette per day and over six months) exposed to smoke due to smoking of family members before you were 20 years old and how many years did that occur?"

Data on death were obtained through the follow-up surveys and by linkage to the database of the Shanghai Death Registry. The underlying cause of each death was assigned according to the international classification of diseases, 9 th revision.

\section{Statistical analysis}

The end date of the observation was set as the date of death for participants who had died, or the date of the last follow-up or 30 June 2004 for those who were still alive-half a year ahead of the last annual linkage with the Shanghai Death Registry, whichever was later.

We used the Cox proportional hazards regression model to estimate hazard ratios and 95\% confidence intervals. ${ }^{15}$ Survival was modelled as a function of age, as it is a better predictor of risk of death than is the duration of follow-up. ${ }^{16}$ Left truncation was set to the date of the baseline survey (for exposure to smoking by husbands) or the date of the first follow-up survey (for exposure at work, in early life from family members, and all three sources of exposure combined). The covariates included in the model were education, occupation, family income, physical activity, body mass index, and intake of meat, vegetables, and fruit. We used the Cox regression model without including the covariates to estimate cumulative mortality. To account for competing risk when estimating cumulative cause specific mortality, we classified the causes of death into three categories-death due to cancer, death due to cardiovascular disease, and death due to all other causes. We used method B of Lunn and McNeil to estimate the cumulative mortality accounting for competing risk of each of the three causes of death. ${ }^{17}$

\section{Results}

Table 1 gives the baseline characteristics of the 72829 women who had never smoked. Table 2 shows data on participants who provided information on environmental tobacco smoke. The number of participants and number of deaths varied when different exposure variables were analysed. Cancer and cardiovascular disease were two of the most common causes of death. Stroke was the leading cause of death due to cardiovascular disease.

Exposure to environmental tobacco smoke was highly prevalent; 83.1\% (49 563/59 675) of women were exposed to environmental tobacco smoke from their husbands, at work, or in early life (or a combination) (table 3). Cumulative all cause mortality was significantly higher in women whose husbands smoked than in those whose husbands did not smoke $(9.1 \% v 7.8 \%$ at age 70 ; $\mathrm{P}=0.009$ ), but other sources of environmental tobacco smoke were not associated with significantly higher all cause mortality. For cause specific mortality with the competing risk accounted for, cumulative mortality due to cardiovascular disease was significantly increased in women whose husbands smoked $(2.2 \%$ $v 1.7 \%$ at age $70 ; \mathrm{P}=0.048$ ) (figure).

Table 4 shows the estimated risks of exposure to environmental tobacco smoke and all cause mortality and cause specific death, adjusted for potential confounders. The adjusted hazard ratios were similar to those where only age was adjusted for. Exposure from husbands (mainly current exposure) was
Table 1 Characteristics of participants in Shanghai women's health study who had never smoked

\begin{tabular}{|c|c|}
\hline Characteristic & No $(\%)$ \\
\hline Age at baseline: & $(n=72829)$ \\
\hline $40-45$ & $24060(33.0)$ \\
\hline $46-50$ & $14263(19.6)$ \\
\hline $51-55$ & $9495(13.0)$ \\
\hline $56-60$ & $7364(10.1)$ \\
\hline $61-65$ & $9958(13.7)$ \\
\hline $66-70$ & 7689 (10.6) \\
\hline Education: & $(n=72820)$ \\
\hline College or higher & $10112(13.9)$ \\
\hline High school & $20589(28.3)$ \\
\hline Middle school & $27132(37.3)$ \\
\hline Less than middle school & 14987 (20.6) \\
\hline Family income: & $(n=72813)$ \\
\hline High & $19772(27.2)$ \\
\hline Middle & $28407(39.0)$ \\
\hline Low & $24634(33.8)$ \\
\hline Marital status: & $(\mathrm{n}=72$ 829) \\
\hline Single & $654(0.9)$ \\
\hline Married & $64881(89.1)$ \\
\hline Widowed & $5233(7.2)$ \\
\hline Separated & $774(1.1)$ \\
\hline Divorced & $1287(1.8)$ \\
\hline Occupation: & $(n=72580)$ \\
\hline Professional & $21183(29.2)$ \\
\hline Clerical & $15014(20.7)$ \\
\hline Farmer, manual worker & $36383(50.1)$ \\
\hline Ever drank alcohol: & $(\mathrm{n}=72829)$ \\
\hline No & $71429(98.1)$ \\
\hline Yes & $1400(1.9)$ \\
\hline Physical activity during adolescence: & $(\mathrm{n}=72$ 829) \\
\hline Little & $15723(21.6)$ \\
\hline Moderate & $37951(52.1)$ \\
\hline Active & $19155(26.3)$ \\
\hline Regular physical activity during past five years: & $(\mathrm{n}=72829)$ \\
\hline No & $47029(64.6)$ \\
\hline Yes & $25800(35.4)$ \\
\hline
\end{tabular}

Not all participants answered all questions.

associated with significantly increased all cause mortality (1.15, 1.01 to 1.31 ), and more strongly with increased mortality due to cardiovascular disease $(1.37,1.06$ to 1.78$)$ and stroke (1.52, 1.08 to 2.15). Exposure to tobacco smoke at work was associated with increased mortality due to cancer (1.19, 0.94 to 1.50$)$, especially lung cancer $(1.79,1.09$ to 2.93). Exposure in early life from family members was associated with increased mortality due to car-

Table 2 Number of deaths in participants in Shanghai women's health study who provided information on environmental tobacco smoke from different sources

\begin{tabular}{|c|c|c|c|}
\hline \multirow[b]{2}{*}{ Cause of death } & \multicolumn{3}{|c|}{ Source of exposure } \\
\hline & $\begin{array}{c}\text { Husbands ( } \mathrm{n}=65 \\
180)^{*}\end{array}$ & $\begin{array}{l}\text { Work or in early life } \\
(n=66520) \dagger\end{array}$ & $\begin{array}{l}\text { All } 3 \text { sources } \\
(n=59675)\end{array}$ \\
\hline All cancers & 586 & 358 & 294 \\
\hline Lung cancer & 106 & 75 & 62 \\
\hline Cardiovascular disease & 272 & 184 & 139 \\
\hline Stroke & 157 & 104 & 79 \\
\hline Coronary heart disease & 48 & 34 & 26 \\
\hline Diabetes & 66 & 43 & 25 \\
\hline Diseases of digestive system & 51 & 32 & 30 \\
\hline Other & 177 & 113 & 94 \\
\hline Total & 1152 & 730 & 582 \\
\hline
\end{tabular}

*Assessed at baseline (1997-2000).

†Assessed at first follow-up (2000-2002). 
Research

\begin{tabular}{|c|c|c|c|c|c|c|}
\hline \multirow{2}{*}{ Source of exposure to tobacco smoke } & \multicolumn{2}{|c|}{ No of participants } & \multicolumn{2}{|c|}{ Cumulative mortality (\%) } & \multirow{2}{*}{$P$ value } & \multirow{2}{*}{ Hazard ratio $(95 \% \mathrm{Cl})^{*}$} \\
\hline & Unexposed & Exposed & Unexposed & Exposed & & \\
\hline \multicolumn{7}{|l|}{ Husband $(n=65180)$} \\
\hline No of participants & 25385 & 39795 & & & & \\
\hline No of deaths & 490 & 662 & 7.82 & 9.07 & 0.009 & 1.16 (1.04 to 1.32$)$ \\
\hline \multicolumn{7}{|l|}{ Cause of death: } \\
\hline Cancer & 254 & 332 & 4.26 & 4.67 & 0.246 & $1.10(0.94$ to 1.30$)$ \\
\hline Cardiovascular disease & 112 & 160 & 1.72 & 2.19 & 0.048 & 1.28 (1.00 to 1.63$)$ \\
\hline Other & 124 & 170 & 1.84 & 2.21 & 0.106 & 1.21 (0.96 to 1.53$)$ \\
\hline \multicolumn{7}{|l|}{ Workplace $(n=66520)$} \\
\hline No of participants & 41008 & 25512 & & & & \\
\hline No of deaths & 522 & 208 & 7.33 & 7.29 & 0.913 & 0.99 (0.84 to 1.17$)$ \\
\hline \multicolumn{7}{|l|}{ Cause of death: } \\
\hline Cancer & 241 & 117 & 3.68 & 4.16 & 0.300 & $1.13(0.90$ to 1.42$)$ \\
\hline Cardiovascular disease & 141 & 43 & 1.80 & 1.48 & 0.271 & $0.82(0.58$ to 1.17$)$ \\
\hline Other & 140 & 48 & 1.84 & 1.66 & 0.547 & $0.90(0.64$ to 1.26$)$ \\
\hline \multicolumn{7}{|l|}{ Family members in early life ( $n=66520$ ) } \\
\hline No of participants & 38798 & 27722 & & & & \\
\hline No of deaths & 458 & 272 & 7.35 & 7.31 & 0.916 & $1.00(0.87$ to 1.17$)$ \\
\hline \multicolumn{7}{|l|}{ Cause of death: } \\
\hline Cancer & 241 & 117 & 4.18 & 3.35 & 0.052 & $0.80(0.64$ to 1.00$)$ \\
\hline Cardiovascular disease & 105 & 79 & 1.51 & 1.99 & 0.066 & $1.32(0.98$ to 1.77$)$ \\
\hline Other & 112 & 76 & 1.67 & 1.96 & 0.278 & 1.18 (0.88 to 1.58$)$ \\
\hline \multicolumn{7}{|l|}{ Exposed to all 3 sources ( $n=59675)$} \\
\hline No of participants & 10112 & 49563 & & & & \\
\hline No of deaths & 129 & 453 & 6.39 & 7.30 & 0.150 & $1.15(0.94$ to 1.41$)$ \\
\hline \multicolumn{7}{|l|}{ Cause of death: } \\
\hline Cancer & 66 & 228 & 3.62 & 3.87 & 0.611 & 1.07 (0.81 to 1.42$)$ \\
\hline Cardiovascular disease & 27 & 112 & 1.16 & 1.66 & 0.092 & 1.44 (0.94 to 2.21) \\
\hline Other & 36 & 113 & 1.62 & 1.77 & 0.632 & $1.10(0.75$ to 1.61$)$ \\
\hline
\end{tabular}

${ }^{*}$ Derived from Cox regression models with age as the timescale (adjusted for age).

diovascular disease (1.26, 0.94 to 1.69$)$. We also analysed the effect of duration of exposure to environmental tobacco smoke on mortality. Significant dose-response relations existed between mortality due to stroke and husband's number of pack years $(\mathrm{P}=0.029)$, between mortality due to lung cancer and total years of exposure at work $(\mathrm{P}=0.003)$, and between mortality due to cardiovascular diseases and total years of exposure in early life $(\mathrm{P}=0.029)$ (table 4). For the 59675 women who provided information on all three sources of exposure, we included all three sources of exposure in the same model for mutual adjustment; the results were similar to those presented in table 4 .

We also analysed the association of environmental tobacco smoke with death due to coronary heart disease. The pattern of association was similar to that for total cardiovascular diseases, but the results were not significant (not shown) because of the small number of deaths due to coronary heart disease (see table 2).

\section{Discussion}

In Chinese women who had never smoked, exposure to tobacco smoke from husbands was associated with increased all cause mortality, especially increased mortality due to cardiovascular disease. Exposure to environmental tobacco smoke at work was associated with increased mortality due to cancer, especially lung cancer.

\section{Relation to other studies}

Epidemiological studies published in the past two decades have indicated that environmental tobacco smoke is associated with lung cancer and coronary heart disease. Recently, the International Agency for Research on Cancer concluded that findings on the risk of lung cancer associated with environmental tobacco smoke were consistent. ${ }^{1}$ On the basis of a review of over 50 studies, they estimated an excess risk of about $20 \%$ for

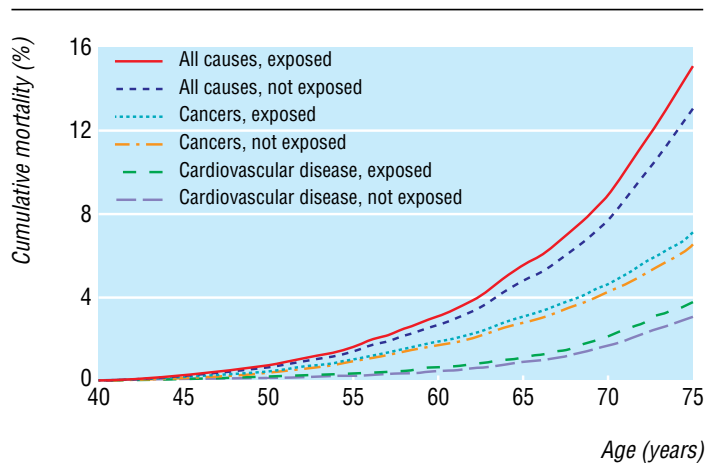

Mortality and exposure to husband's tobacco smoke in Chinese women who had never smoked 
Table 4 Association between mortality and exposure to environmental tobacco smoke in the Shanghai women's health study. Values are hazard ratios and $95 \%$ confidence intervals*

\begin{tabular}{|c|c|c|c|c|c|}
\hline \multirow{2}{*}{ Type of exposure } & \multirow{2}{*}{ All causes of death } & \multicolumn{4}{|c|}{ Cause of death } \\
\hline & & Cancer (all types) & Lung cancer & Cardiovascular disease & Stroke \\
\hline \multicolumn{6}{|l|}{ Husbandt ( $\mathrm{n}=65 \mathrm{180}$ ) } \\
\hline Ever exposed & 1.11 (0.99 to 1.25$)$ & 1.08 (0.91 to 1.27$)$ & 1.09 (0.74 to 1.61$)$ & $1.18(0.92$ to 1.51$)$ & 1.33 (0.96 to 1.84$)$ \\
\hline Former & 1.01 (0.85 to 1.22$)$ & 1.15 (0.90 to 1.47$)$ & 1.15 (0.65 to 2.04$)$ & 0.75 (0.49 to 1.12$)$ & 0.92 (0.54 to 1.52) \\
\hline Current & 1.15 (1.01 to 1.31$)$ & 1.05 (0.88 to 1.26$)$ & 1.06 (0.69 to 1.63$)$ & 1.37 (1.06 to 1.78$)$ & 1.52 (1.08 to 2.15) \\
\hline \multicolumn{6}{|l|}{ Pack years of exposure: } \\
\hline$<8.8$ & 1.14 (0.94 to 1.38$)$ & 1.26 (0.98 to 1.63$)$ & 1.62 (0.86 to 2.70$)$ & $1.10(0.72$ to 1.69$)$ & 1.35 (0.79 to 2.31$)$ \\
\hline $8.8-17.9$ & 1.09 (0.91 to 1.31$)$ & 1.03 (0.80 to 1.33$)$ & 1.39 (0.81 to 2.39 ) & $1.12(0.76$ to 1.64$)$ & 1.25 (0.76 to 2.07) \\
\hline$\geq 18.0$ & 1.11 (0.97 to 1.28$)$ & 1.02 (0.84 to 1.25$)$ & 0.79 (0.48 to 1.31$)$ & $1.22(0.93$ to 1.61$)$ & 1.36 (0.94 to 1.96$)$ \\
\hline Trend test & $P=0.155$ & $\mathrm{P}=0.811$ & $P=0.589$ & $P=0.080$ & $P=0.029$ \\
\hline \multicolumn{6}{|l|}{ Workplace $(\mathrm{n}=66520$ ) } \\
\hline Ever exposed & 1.08 (0.91 to 1.28$)$ & 1.19 (0.94 to 1.50$)$ & 1.79 (1.09 to 2.93 ) & 0.92 (0.64 to 1.32) & $0.73(0.44$ to 1.20$)$ \\
\hline \multicolumn{6}{|l|}{ Years of exposure: } \\
\hline$<10$ & 1.04 (0.79 to 1.37$)$ & 1.03 (0.70 to 1.51$)$ & 1.58 (0.73 to 3.45$)$ & 0.86 (0.47 to 1.57$)$ & $0.47 \quad(0.17$ to 1.29$)$ \\
\hline $10-24$ & 1.06 (0.82 to 1.38$)$ & 1.20 (0.85 to 1.70$)$ & 1.28 (0.57 to 2.87$)$ & 0.96 (0.56 to 1.65$)$ & 0.95 (0.47 to 1.90) \\
\hline$>24$ & 1.14 (0.89 to 1.45$)$ & 1.31 (0.95 to 1.81$)$ & 2.45 (1.32 to 4.56$)$ & 0.93 (0.54 to 1.58$)$ & 0.74 (0.35 to 1.56$)$ \\
\hline Trend test & $\mathrm{P}=0.292$ & $\mathrm{P}=0.076$ & $\mathrm{P}=0.003$ & $P=0.864$ & $\mathrm{P}=0.520$ \\
\hline \multicolumn{6}{|l|}{ In early life $(\mathrm{n}=66520$ ) } \\
\hline Ever exposed & 0.98 (0.85 to 1.14$)$ & 0.79 (0.63 to 0.98$)$ & 0.88 (0.55 to 1.43$)$ & 1.26 (0.94 to 1.69) & 1.10 (0.74 to 1.63$)$ \\
\hline \multicolumn{6}{|l|}{ Years of exposure: } \\
\hline$<20$ & 0.96 (0.80 to 1.14 ) & 0.77 (0.59 to 1.01$)$ & 0.88 (0.50 to 1.55$)$ & 1.21 (0.86 to 1.70$)$ & 0.91 (0.56 to 1.47) \\
\hline$\geq 20$ & 1.03 (0.83 to 1.28$)$ & 0.81 (0.59 to 1.11$)$ & 0.89 (0.45 to 1.77$)$ & $1.36(0.90$ to 2.05$)$ & 1.46 (0.86 to 2.45) \\
\hline Trend test & $P=0.807$ & $\mathrm{P}=0.077$ & $P=0.980$ & $\mathrm{P}=0.029$ & $\mathrm{P}=0.342$ \\
\hline \multicolumn{6}{|l|}{ All 3 sources ( $n=59$ 675) } \\
\hline Ever exposed & 1.15 (0.95 to 1.41$)$ & 1.06 (0.80 to 1.40$)$ & 1.03 (0.57 to 1.87$)$ & 1.45 (0.95 to 2.22) & 1.64 (0.91 to 2.95) \\
\hline \multicolumn{6}{|l|}{ Source of exposure: } \\
\hline Husband only & 1.26 (0.99 to 1.59$)$ & 1.25 (0.90 to 1.74$)$ & 0.89 (0.42 to 1.92$)$ & $1.52(0.92$ to 2.50$)$ & 2.21 (1.15 to 4.24$)$ \\
\hline Early life only & 0.89 (0.61 to 1.28$)$ & 0.41 (0.20 to 0.82$)$ & 0.21 (0.03 to 1.61$)$ & 1.82 (0.96 to 3.43$)$ & 1.86 (0.77 to 4.46$)$ \\
\hline Workplace only & $1.28 \quad(0.92$ to 1.79$)$ & 1.71 (1.13 to 2.58$)$ & 2.23 (0.95 to 5.27$)$ & $0.80(0.32$ to 1.96$)$ & 0.49 (0.11 to 2.18) \\
\hline Husband+early life & 1.07 (0.82 to 1.40$)$ & 0.91 (0.61 to 1.35$)$ & 0.81 (0.34 to 1.94$)$ & 1.42 (0.82 to 2.45$)$ & 1.25 (0.56 to 2.77) \\
\hline Husband+workplace & 0.99 (0.69 to 1.42$)$ & 0.81 (0.48 to 1.36$)$ & 1.24 (0.44 to 3.51$)$ & 1.30 (0.62 to 2.74$)$ & 1.47 (0.55 to 3.91$)$ \\
\hline Early life+workplace & 1.13 (0.74 to 1.72$)$ & 1.00 (0.56 to 1.79$)$ & 0.77 (0.17 to 3.43$)$ & $1.11(0.42$ to 2.93$)$ & 0.88 (0.20 to 3.91) \\
\hline All & 1.38 (1.00 to 1.89$)$ & 1.14 (0.73 to 1.79$)$ & 2.17 (0.94 to 5.03$)$ & 1.74 (0.89 to 3.40$)$ & 2.16 (0.91 to 5.13$)$ \\
\hline
\end{tabular}

*Derived from Cox regression models with age as the time to scale; also adjusted for education, occupation, family income, physical activity, body mass index, and intake of meat, vegetables, and fruit.

†Regardless of whether exposed to other sources.

people who have a spouse who smokes. The findings on other cancers were inconsistent, however. Since 1990, several meta-analyses of the association between environmental tobacco smoke and coronary heart disease have been published and have yielded relative risks of $1.1-1.3 \cdot{ }^{18-22}$ Few studies have examined all cause mortality associated with environmental tobacco smoke. Recent studies reported that exposure to environmental smoke was associated with a $15 \%$ increase in all cause mortality in people aged $45-74$ in New Zealand and a 34\% increase in people aged 60 or more in Hong Kong. ${ }^{6} 7$

Most previous epidemiological studies on the relation between environmental tobacco smoke and cardiovascular disease have focused on coronary heart disease, a leading cause of death in Western countries. Only a few studies have examined the relation of environmental tobacco smoke to stroke, a leading cause of death and disability in China. ${ }^{23}{ }^{24}$ We found a positive association of stroke with exposure via husbands who smoke, especially current exposure. This finding confirmed our previous report, which was based on cross sectional survey data, that women who do not smoke but live with husbands who currently smoke had an increased prevalence of stroke. ${ }^{23}$ Exposure to environmental tobacco smoke was also associated with a moderately increased risk of all cause mortality and mortality due to lung cancer and cardiovascular diseases, which is generally consistent with most previous studies.

\section{Strengths and limitations}

The strengths of our study include a high participation rate $(92.7 \%)$ at baseline recruitment, so that our data are representative of the general population; a large sample size with a low proportion of current smokers, divorced women, and unmarried women; and a high proportion of environmental exposure to tobacco smoke $(83.1 \%)$. Other strengths are complete assessment of exposure to environmental tobacco smoke from husbands, at work, and in early life from family members; extensive baseline and follow-up data on smoking and potential confounders; and appropriate use of the Cox regression model with complete control for the effect of age and adjustment of important potential confounders. ${ }^{16}$ The inconsistency of previous findings has resulted, at least in part, from methodological problems. These include incomplete and inaccurate measurement of environmental tobacco smoke $^{1 / 3}$ and insufficient control of confounding due to a lack of information about confounders, such as dietary factors, ${ }^{1}$ and the use of inappropriate regression models. ${ }^{811}$

Our results were based on data obtained after a short follow-up time (average 5.7 years), so that the power of our study was not optimal, especially for the evaluation of cause specific mortality. Although our results generally show that environmental tobacco smoke has adverse effects on all cause mortality and mortality due to cancer and cardiovascular disease, associations 
with different sources of exposure varied. For example, exposure to tobacco smoke at work was associated with mortality due to lung cancer but not with mortality due to cardiovascular disease. In contrast, exposure in early life was associated with mortality due to cardiovascular disease but not with mortality due to lung cancer. Exposure to environmental tobacco smoke at different times of life may contribute to the risk of different diseases. Environmental tobacco smoke could also be a surrogate measure of other risk factors that were not adjusted for, such as carcinogens at work. As with previous studies, errors of measurement and in assessing environmental tobacco smoke may have occurred, especially for exposure at work, which is ubiquitous, and for exposure in early life, where long term recall might not be accurate. We tried to reduce potential recall bias, a serious limitation in most retrospective studies, by assessing exposure at the beginning of our study. The inclusion of biological markers for exposure to smoke, such as concentrations of cotinine in the blood, might increase the accuracy of assessing environmental tobacco smoke. However, the value of cotinine measurement in assessing long term exposure to environmental tobacco smoke is unclear. A recent study found that self reported exposure to environmental tobacco smoke was associated with the risk of lung cancer but cotinine concentrations were not. ${ }^{4}$

\section{Conclusions}

Environmental tobacco smoke was related to a moderately increased risk of all cause mortality and mortality due to lung cancer and cardiovascular disease. Given the high prevalence of exposure to environmental tobacco smoke $(83.1 \%)$ in this population, a moderate association with a hazard ratio of 1.15 would yield an attributable risk in the population of $11.1 \%$. The impact of environmental tobacco smoke on all cause mortality could be substantial.

Contributors: WW, XOS, Y-TG, and WZ helped design the study and analyse the data. XOS, Y-TG, GY, QL, HL, and WZ helped in data collection and field operations. All authors helped prepare the manuscript.

\section{What is already known on this topic}

The excess risk of coronary heart disease and lung cancer from exposure to environmental tobacco smoke is about $15-35 \%$

Exposure to environmental tobacco smoke may also increase mortality, the risk of other cardiovascular diseases such as stroke, and other cancers, though evidence is scarce

\section{What this study adds}

Exposure to tobacco smoke from husbands was associated with increased all cause mortality and mortality due to cardiovascular disease

Exposure to environmental tobacco smoke at work was associated with increased mortality due to cancer, especially lung cancer
Funding: Supported by NIH grant RO1CA70867.

Competing interests: None declared.

Ethical approval: Institutional review boards for human research in Shanghai Cancer Institute, China and Vanderbilt University, US.

1 International Agency for Research on Cancer. Tobacco smoking and involuntary smoking. Lyon: IARC, 2004. (IARC monographs on the evaluation of carcinogenic risks to humans. Vol 83.)

2 Taylor AE, Johnson DC, Kazemia H. Environmental tobacco smoke and cardiovascular disease. Circulation 1992;86:1-4

3 Centers for Disease Control and Prevention. Women and smoking: a report of the surgeon general (executive summary). MMWR Recomm Rep 2002;51(RR-12):1-13.

4 Vineis P, Airoldi L, Veglia P, Olgiati L, Pastorelli R, Autrup H, et al. Environmental tobacco smoke and risk of respiratory cancer and chronic obstructive pulmonary disease in former smokers and never smokers in the EPIC prospective study. BMJ 2005;330:277-80.

5 Johnson KC. Accumulating evidence on passive and active smoking and breast cancer risk. Int J Cancer 2005; 117:619-28.

6 Hill S, Blakely T, Kawachi I, Woodward A. Mortality among "never smokers" living with smokers: two cohort studies, 1981-4 and 1996-9. BMJ 2004;328:988-9.

7 McGhee SM, Ho SY, Schooling M, Ho LM, Thomas GN, Hedley AJ, et al. Mortality associated with passive smoking in Hong Kong. BMJ 2005;330:287-8.

8 Enstrom JE, Kabat GC. Environmental tobacco smoke and tobacco related mortality in a prospective study of Californians, 1960-98. BMJ 2003;326:1057-61.

9 Vaidya JS. Passive smoking: study was flawed from outset. BMJ 2003;327:501.

10 Glaser JH. Passive smoking: inverse correlation of smoking and education should have raised suspicion. BMJ 2003;327:502.

11 Milne E. Passive smoking: doubts about effectiveness of age adjustment. BMJ 2003;327:502

12 Tonks A. Summary of rapid responses. BMJ 2003;327:505

13 Kawachi I, Colditz GA. Invited commentary: confounding, measurement error, and Kawachi I, Colditz GA. Invited commentary: confounding, measurement error
publication bias in studies of passive smoking. Am J Epidemiol 1996;144:909-15.

14 Zheng W, Chow WH, Yang G, Jin F, Rothman N, Blair A, et al. The Shanghai women's health study: rationale, study design, and baseline characteristics. Am J Epidemiol 2005;162:1123-31.

15 Cox DR. Regression models and life-tables (with discussion). J R Stat Soc Ser B 1972;34:187-220.

16 Korn EL, Graubard BI, Midthune D. Time-to-event analysis of longitudinal follow-up of a survey: choice of the time-scale. Am J Epidemiol 1997;145:72-80.

17 Lunn M, McNeil D. Applying Cox regression to competing risks. Biometrics 1995;51:524-32.

18 Kaur S, Cohen A, Dolor R, Coffman CJ, Bastian LA. The impact of environmental tobacco smoke on women's risk of dying from heart disease: a meta-analysis.J Womens Health 2004;13:888-97.

19 Thun M, Henley J, Apicella L. Epidemiologic studies of fatal and nonfatal cardiovascular disease and ETS exposure from spousal smoking. Environ Health Perspect 1999;107(suppl 6):841-6.

20 Wells AJ. Passive smoking and coronary heart disease. N Engl J Med 1999;:341:697-8.

21 He J, Vupputuri S, Allen K, Prerost MR, Hughes J, Whelton PK. Passive smoking and the risk of coronary heart disease-a meta-analysis of epidemiologic studies. $N$ Engl J Med 1999;340:920-6.

22 Law MR, Morris JK, Wald NJ. Environmental tobacco smoke exposure and ischaemic heart disease: an evaluation of the evidence. BMJ 1997;315:973-80.

23 Zhang X, Shu XO, Yang G, Li HL, Xiang YB, Gao YT, et al. Association of passive smoking by husbands with prevalence of stroke among Chinese women nonsmokers. Am J Epidemiol 2005;161:213-8.

24 Whincup PH, Gilg JA, Emberson JR, Jarvis MJ, Feyerabend C, Bryant A, et al. Passive smoking and risk of coronary heart disease and stroke: prospective study with cotinine smoking and risk of coronary heart
measurement. BMJ 2004;329:200-5.

(Accepted 14 April 2006)

doi $10.1136 /$ bmj.38834.522894.2F

Department of Medicine, Vanderbilt-Ingram Cancer Center, Vanderbilt University School of Medicine, Nashville, TN 37232, USA

Wanqing Wen research assistant professor

Xiao Ou Shu professor

Gong Yang research assistant professor

Wei Zheng professor

Department of Epidemiology, Shanghai Cancer Institute, Shanghai, China 20032

Yu-Tang Gao professor

Qi Li research associate

Honglan $\mathrm{Li}$ research associate

Correspondence to: W Wen wanqing.wen@vanderbilt.edu 